\title{
Detection of parasitic particles in domestic and urban wastewaters and assessment of removal efficiency of treatment plants in Tehran, Iran
}

\author{
Kareem Hatam-Nahavandi ${ }^{1}$, Amir Hossein Mahvi ${ }^{2}$, Mehdi Mohebali ${ }^{1,3}$, Hossein Keshavarz ${ }^{1}$, Iraj Mobedi ${ }^{1}$ \\ and Mostafa Rezaeian ${ }^{1 *}$
}

\begin{abstract}
Background: In recent years, decreasing annual rainfalls in some countries and population growth have led to a shortage of freshwater resources. Thus, recycled wastewaters has been suggested for agricultural activities. Contamination of wastewaters with pathogens is a major concern for the use of these waters. This study aimed to (i) investigate the occurrence of helminth eggs and protozoan (oo)cysts in human and livestock wastewaters, and (ii) evaluate the parasite removal efficiencies of urban and slaughterhouse treatment plants in Tehran province, Iran. One hundred and eight samples were collected from five urban and domestic wastewater treatment plants in Iran. Wastewater samples were concentrated by centrifugal-concentration and filtration methods.
\end{abstract}

Results: The quantity of helminths egg and protozoa (oo)cyst per liter of urban raw wastewater ranged from $1.2 \times 10^{1}$ to $2.9 \times 10^{1}$ and from $9.6 \times 10^{2}$ to $1.9 \times 10^{3}$, respectively. The number of eggs and (oo)cysts per liter of animal raw wastewater ranged from $1.6 \times 10^{3}$ to $4.9 \times 10^{3}$ and $3.1 \times 10^{4}$ to $6.0 \times 10^{4}$, respectively. The helminths and protozoa identified in urban treatment plants included hookworms, Hymenolepis and Rhabditis (or probably Strongyloides), Entamoeba, Isospora, Giardia, Chilomastix and Cryptosporidium, while in slaughterhouses Trichuris, Trichostrongylus, Moniezia, Dicrocoelium, Fasciola, Entamoeba, Cryptosporidium, Eimeria and Giardia were isolated. The overall removal efficiency of eggs and (oo)cysts in the treatment plants ranged from 94.8 to $95.7 \%$ and from 79.3 to $85.8 \%$, respectively.

Conclusion: The study results revealed that the efficacy of removal of nematode eggs, and not protozoan (oo)cysts, in urban wastewater treatment plants, is in compliance with the WHO parasitological guideline ( $<1$ nematode per liter) required for unrestricted irrigation.

Keywords: Protozoan (oo)cyst, Helminth egg, Wastewater treatment plant, Slaughterhouse, Iran

\section{Background}

Water is life. In 2025, water shortages will be more prevalent among poorer regions such as Africa and parts of Asia, where resources are limited, anuall rainfall is low, population growth is rapid, and water concumption is high [1]. Under these circumstances, treated wastewaters can be used for irrigation of parks, playgrounds and agricultural farmlands [2]. Contamination of wastewaters with pathogens and chemical pollutants is a major

\footnotetext{
* Correspondence: rezaiian@sina.tums.ac.ir

'Department of Medical Parasitology and Mycology, School of Public Health,

Tehran University of Medical Sciences, Tehran, Iran

Full list of author information is available at the end of the article
}

concern for the use of these waters. Parasitic particles, including the helminth ova and protozoan (oo)cyst, are detected more frequently in wastewater than in other surface waters and are resistant to chlorination or ozonation used commonly in the water and wastewater treatment systems [3,4]. Pathogenic protozoa are major causes of human gastroenteritis transmitted by water and significant challenges of public health worldwide [5]. Several water-borne giardiasis, amoebiasis, cryptosporidiosis, balantidiosis, cyclosporidiosis and microsporidiosis outbreaks have been reported throughout the world [6]. The first outbreak of plant-borne fascioliasis, the biggest in the world, occurred in Iran (Bandar Anzali) in

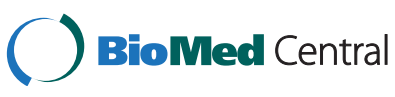

(c) 2015 Hatam-Nahavandi et al.; licensee BioMed Central. This is an Open Access article distributed under the terms of the Creative Commons Attribution License (http://creativecommons.org/licenses/by/4.0), which permits unrestricted use, distribution, and reproduction in any medium, provided the original work is properly credited. The Creative Commons Public Domain Dedication waiver (http://creativecommons.org/publicdomain/zero/1.0/) applies to the data made available in this article, unless otherwise stated. 
February 1988. Total number of infected inhabitants estimated to be 10,000 [7]. All of trematodes have an indirect life cycle, unlike nematodes, and humans can't be infected by eating the eggs of these flukes, therefore, the efficiency of wastewater treatment plants in removing eggs can lead to interruption of transmission cycle. Of all the helminth eggs likely to be present in wastewaters, Ascaris, Trichuris and hookworm are of particular public health concern because of severe socioeconomic consequences of an estimated 39 million DALYs (disability adjusted life year) lost to these infections [8]. Generally, parasite removal in wastewater has been synonymous with the removal of intestinal nematode ova, particularly those of Ascaris, Trichuris and the hookworms, because they occur commonly and simple purification and microscopic identification methods were available to determine their present. Many of these parasites are zoonotic, thus, can be realized to the importance of various studies based on the removal efficiency of domestic and municipal wastewater treatment plants. Many studies have been conducted to determine the prevalence of these pathogens in surface waters and vegetables in Iran [9-12]. The objectives of the present study were to investigate the occurrence of helminth eggs, protozoan (oo)cysts and pseudoparasitic structures in human and livestock wastewaters, and to evaluate the egg and (oo)cyst removal efficiencies of urban and slaughterhouse wastewater treatment plants by egg and (oo)cyst recoveries in both influent- and final effluent wastewaters.

\section{Methods}

\section{Study sites and samples}

Wastewater samples were collected from three municipal treatment plants and two slaughterhouse treatment plants.

Municipal wastewater treatment plants were located at the west and southwest of Tehran: Shahrak-e Ekbatan (WWTP1), Shahrak-e Gharb (WWTP2) and south Tehran wastewater treatment plant (WWTP3), and recycled water discharged into creek of firoozabad, Sheikh-Fazlollah highway surface water channel and Varamin agricultural lands, respectively.

Domestic wastewater treatment plants were located in one suburb area of Tehran: Meisam-robat-dam (SWWTP4) and Dam-pak (SWWTP5).

The animals slaughtered in these two slaughterhouses were included cattle, sheep and goat, and the plants treated only domestic wastewater and reclaimed water was reused for the irrigation of Shahriār agricultural farm lands.

The main features in each of the five treatment plants are described in Table 1.

Grab samples of untreated (5 L each) and treated (10 L each) wastewater were collected at the inlet and outlet points of treatment plants monthly once, from December 2013 to November 2014.

The determination of samples volume was conducted in compliance with Analysis of Wastewater for Use in Agriculture - A Laboratory Manual of Parasitological and Bacteriological Techniques [2].

Water samples were collected in carboys and transported to the intestinal protozoan laboratory of the faculty of public health at the Tehran University of Medical Sciences (TUMS) where they were stored at $4^{\circ} \mathrm{C}$ until used for the analyses. The samples analyses were completed within 7 days. To reduce the potential for crosscontamination between samples, all sampling carboys used for raw and treated effluent were kept separate.

\section{Recovery efficiency of Giardia cyst concentration procedures}

The cyst recovery efficiency of four concentration methods was evaluated and compared to demonstrate acceptable method performance and included (i) modified Bailenger method (MB), as recommended by WHO in "Analysis of wastewater for agricultural use" [2] (ii) scraping and rinsing of membrane method (RM), (iii) acetonedissolution method (ADM) [13], and (iv) centrifugal(water-ether) concentration method (CC method) [14].

For each concentration method, six aliquots of 5 litres (untreated and treated) samples were collected. For each concentration procedure, two aliquots of raw and two aliquots of treated samples were used as matrix spikes and were seeded with estimated numbers of Giardia cysts.

The cysts used in assays were a gift from Dr. Meamar, School of Medicine, Iran University of Medical Sciences, Tehran, Iran, and were isolated and purified from feces of diarrheal patients by sucrose flotation (specific gravity of 1.18). The number of cysts $\left(\sim 4 \times 10^{3}\right)$ was determined by microscopic examination and the pellet was suspended in one milliliter deionized water.

All of seeded and unseeded samples were sieved through a sries of stainless steel and polyester meshes of 40 (pore size 400- $\mu \mathrm{m}$ ), 50 (pore size $297-\mu \mathrm{m}$ ), 200 (pore size $74-\mu \mathrm{m}$ ) and 400 (pore size $37-\mu \mathrm{m}$ ) before filtration to avoid filter blockage by large particles.

The first set of raw (2 seeded and 1 unseeded) and treated ( 2 seeded and 1 unseeded) samples were transferred to $5000 \mathrm{ml}$ separatory funnel (decanter) (which was designed for this purpose, with two valves built in the bottom of the funnel) and allowed to settle for 24 hours, separately during the consecutive days. The sediments were transferred to $50 \mathrm{ml}$ conical centrifuge tubes through the valves in the bottom of the funnel and centrifuged at $1000 \times \mathrm{g}$ for 15 minutes and further processed by modified Bailenger method as described by Mahvi and Kia [10]. 
Table 1 The main characteristics of the five wastewater treatment plants

\begin{tabular}{|c|c|c|c|c|c|c|c|c|c|c|}
\hline \multirow{2}{*}{$\begin{array}{l}\text { Wastewater } \\
\text { treatment } \\
\text { plants }\end{array}$} & \multirow{2}{*}{$\begin{array}{l}\text { Population } \\
\text { served }\end{array}$} & \multirow[t]{2}{*}{ Primary treatment } & \multirow[t]{2}{*}{ Secondary treatment } & \multirow{2}{*}{$\begin{array}{l}\text { Tertiary treatment } \\
\text { and disinfection }\end{array}$} & \multicolumn{3}{|c|}{ Biochemical parameter } & \multicolumn{2}{|c|}{ Water turbidity* } & \multirow[t]{2}{*}{ Use of treated water } \\
\hline & & & & & $\begin{array}{l}\text { Flow rate } \\
\left(\mathrm{m}^{3} / \mathrm{s}\right)\end{array}$ & $\begin{array}{l}\mathrm{BOD}^{* * *} \\
(\mathrm{mg} / \mathrm{L})\end{array}$ & $\begin{array}{l}\mathrm{TSS}^{* * * *} \\
(\mathrm{mg} / \mathrm{L})\end{array}$ & influent & effluent & \\
\hline WWTP1 & 100000 & $\begin{array}{l}\text { Screening and grit } \\
\text { removal }\end{array}$ & $\begin{array}{l}\text { Activated sludge and } \\
\mathrm{A} 2 / \mathrm{O}^{* * * * *}\end{array}$ & $\begin{array}{l}\text { Sand filtration followed } \\
\text { by chlorination }\end{array}$ & 0.46 & $<6$ & $<30$ & High & Moderate & Discharged into creek \\
\hline WWTP2 & 85000 & $\begin{array}{l}\text { Screening and grit } \\
\text { removal }\end{array}$ & $\begin{array}{l}\text { Conventional activated } \\
\text { sludge }\end{array}$ & Chlorination & 0.27 & $<30$ & $<30$ & High & Moderate & $\begin{array}{l}\text { Discharged to the highway } \\
\text { surface water channel }\end{array}$ \\
\hline WWTP3 & 2100000 & $\begin{array}{l}\text { Screening, grit removal } \\
\text { and sedimentation }\end{array}$ & $\begin{array}{l}\text { Trickling filter followed by } \\
\text { activated sludge }\end{array}$ & $\begin{array}{l}\text { Chlorination and UV } \\
\text { radiation }\end{array}$ & 5.2 & 28 & 28 & High & Moderate & Agriculture irrigation \\
\hline SWWTP4 & $N D^{* *}$ & Sedimentation & $\begin{array}{l}\text { Activated sludge and } \\
\text { oxidation with } \mathrm{O}_{2}\end{array}$ & Chlorination & ND & ND & ND & High & Moderate & Agriculture irrigation \\
\hline SWWTP5 & ND & Sedimentation & $\begin{array}{l}\text { Activated sludge and } \\
\text { oxidation with } \mathrm{O}_{2}\end{array}$ & Chlorination & ND & ND & ND & High & Moderate & Agriculture irrigation \\
\hline
\end{tabular}


The second set of test samples ( 2 raw seeded, 1 raw unseeded, 2 treated seeded and 1 treated unseeded) were filtered by membrane filters (pore size $0.8-\mu \mathrm{m}, 50-\mathrm{mm}$ diameter; Sartorius, Germany), entrapped particles were achieved by scraping the membrane with a smooth-edged plasticine molder and rinsing with PBS elution fluid ( $\mathrm{pH}$ 7.4) (containing $0.1 \%$ Tween-80 and antifoam agent B) and centrifugation $\left(2100 \times g, 10 \mathrm{~min}, 4^{\circ} \mathrm{C}\right)(\mathrm{RM}$ method).

The third set of test samples ( 3 raw and 3 untreated) were concentrated by filtration on cellulose-acetate membrane filters (pore size $0.8-\mu \mathrm{m}, 50-\mathrm{mm}$ diameter; Sartorius, Germany) by vacuum pump (model XX 5522050, Millipore). The membrane filters with entrapped particles transferred to a $50 \mathrm{ml}$ conical centrifuge tube, dissolved in acetone and centrifuged $\left(3000 \times g, 10 \mathrm{~min}, 4^{\circ} \mathrm{C}\right)$. The supernatant fluid was discarded by pipette Pasteur, and the pellet was successively resuspended and centrifuged in 95\% ethanol, 70\% ethanol, and eluting solution ( $\mathrm{pH}$ 7.4). The eluting solution consisted of $0.1 \%$ ( $\mathrm{vol} / \mathrm{vol}$ ) Tween-80 detergent, $0.1 \%(\mathrm{w} / \mathrm{v})$ sodium dodecyl sulfate, $\mathrm{NaCl}, \mathrm{KH}_{2} \mathrm{PO}_{4}, \mathrm{Na}_{2} \mathrm{HPO}_{4} \cdot 12 \mathrm{H}_{2} \mathrm{O}$ and $0.001 \%$ (vol/vol) antifoam agent $\mathrm{B}$ (Sigma-Aldrich) (ADM method).

Fourth set of test samples (3 raw and 3 untreated) were centrifuged $\left(2100 \times g, 15 \mathrm{~min}, 4^{\circ} \mathrm{C}\right)$, and the sediment was concentrated by water-ether concentration procedure following the steps described below.

Microscopic enumeration of cysts was performed in a Thoma counting cell at a magnification of $\times 400$.

The matrix spike recovery was determined from the simple formula as described by Skotarczak [15].

\section{Parasite particles concentration}

The wastewater samples were sieved through a polyester mesh of $40(400 \mu \mathrm{m})$ to remove large particles.

Raw wastewater samples were centrifuged $(2100 \times g$, $15 \mathrm{~min}, 4^{\circ} \mathrm{C}$ ) in a $4 \times 500 \mathrm{ml}$-capacity-swinging-bucket rotor of a refrigerated centrifuge (Beckman, GS-6R Centrifuge).

The supernatant fluids were carefully aspirated by vacuum pump, without disturbing the sediment and about $100 \mathrm{ml}$ of supernatant was left on top of the sediment at the bottom of the canisters (Beckman Aerosolve ${ }^{\oplus}$ Cannisters).

The residues were transferred to $50 \mathrm{ml}$ conical centrifuge tubes and centrifuged as before.

A water-ether concentration procedure was performed with $30 \mathrm{ml}$ deionized water and $9 \mathrm{ml}$ diethyl ether $(\mathrm{CC}$ method) [16]. This concentration method was followed by flotation with zinc sulfate $\left(\mathrm{ZnSo}_{4} \cdot 7 \mathrm{H}_{2} \mathrm{O}\right)(\mathrm{w} / \mathrm{v})$ (specific gravity 1.364) [17].

The upper layer of the flotation solution was decanted into a container, and this solution was diluted with water to lower the specific gravity of the solution to below that of the protozoan (oo)cysts and helminth eggs, and then the (oo)cysts and eggs were collected in the sediment after centrifugation.

The other hand, treated samples were filtered by cellulose-acetate membrane filter (pore size $0.8-\mu \mathrm{m}, 50$ $\mathrm{mm}$ diameter; Sartorius, Germany) to retain the particles. Sample elution was achieved by scraping the membranes with a smooth-edged plasticine molder and rinsing with PBS elution fluid (containing 0.1\% Tween 80 and $0.001 \%$ antifoam agent B). The eluate was collected in a clean glass petri-dish and transferred to a 50$\mathrm{ml}$ centrifuge tube and centrifuged at $2100 \times g$ for $10 \mathrm{~min}$.

Microscopic examination and enumeration of (oo) cysts and eggs was performed in a Thoma counting cell at 400× magnification for Giardia cysts and other protozoan (oo)cysts and in a McMaster counting cell (weber England) at 100× magnification for helminthic eggs [18].

Protozoan (oo)cysts and helminth eggs were identified by morphometric parasitological criteria including the size, which was measured by a calibrated microscope, and shape of eggs and (oo)cysts at 100×, 400× and $1000 \times$ magnifications.

\section{Data analysis}

Results of egg and (oo)cyst quantitation were analyzed with Microsoft Excel (version 2010) and Statistical Package for Social Science version 22 (IBM SPSS Inc., Chicago, IL, USA). Kolmogorov-Smirnov test (test of normality) was realized prior to Student's $t$-test (Paired $T$-test). Geometric and arithmetic means were also calculated. To evaluate the (oo)cyst and egg removal efficiency of treatment plants, the logarithm of egg and (oo) cyst concentrations were calculated and the difference between the number of eggs and (oo)cysts present in the influent and in the effluent samples was considered. A $p$-value $<0.05$ was considered statistically significant.

\section{Results}

\section{Recovery efficiency of Giardia cysts in test samples}

Figure 1 shows the results as the mean percentage recovery and $\pm \mathrm{SD}$, and co-efficient of variance.

The microscopic assessment and cyst enumeration results show that $\mathrm{CC}$ method has the highest cyst recovery at $96.1 \%( \pm 0.7)$ and $95( \pm 1.4)$ for raw and treated samples, respectively (Figure 1).

Recoveries of cysts were higher when using RM method than when using ADM method.

The acetone-dissolution method, due to the formation of a hardened pellet (solid robbery pellet) in the bottom of the tube after the centrifugation step that has interfered with the detection of cysts, exhibited cyst recovery of less than expected.

Background solids from the raw test samples contributed to filter blockage for both the scraping and rinsing 


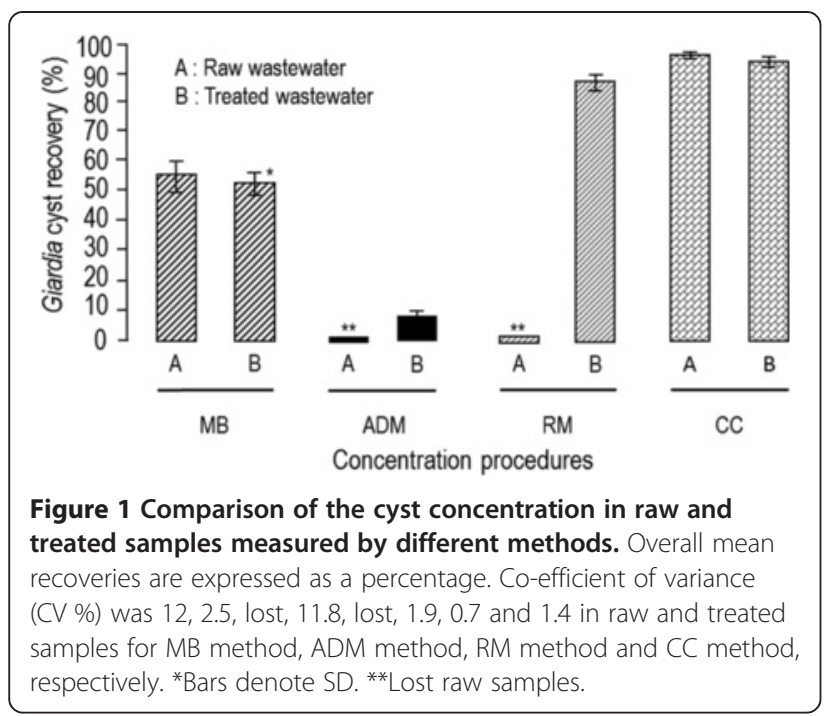

of membrane method and the acetone-dissolution method, and their results were excluded.

The RM method produced the second highest recovery with $88 \%( \pm 1.6)$ cysts isolated for treated samples. The MB method produced the third highest cysts recovery with $55 \%( \pm 7.0)$ and $56.4( \pm 1.4)$ for raw and treated test samples.

The ADM method exhibited cyst recovery of $10.7 \%$ $( \pm 1.2)$ for treated test samples.

Interestingly, a large number of trophozoite forms of protozoa including amoeba, flagellate and cilliate, and a few protozoan cysts, such as Bodo spp., Entamoeba spp. and Giardia duodenalis were found in the supernatant remaining from the modified Bailenger method.

\section{Frequency and distribution of parasitic particles in raw wastewaters}

Eggs, (oo)cysts and pseudoparasitic structures detected in raw and treated wastewaters are shown in Figures 2, 3 and 4.

(Oo)cysts and eggs were detected in wastewater influents of all plants throughout the year.

In all plants, the highest and the lowest number of (oo)cysts and eggs were found in autumn and summer, respectively.

The estimated number of eggs and (oo)cysts per liter of raw wastewaters from urban treatment plants ranged

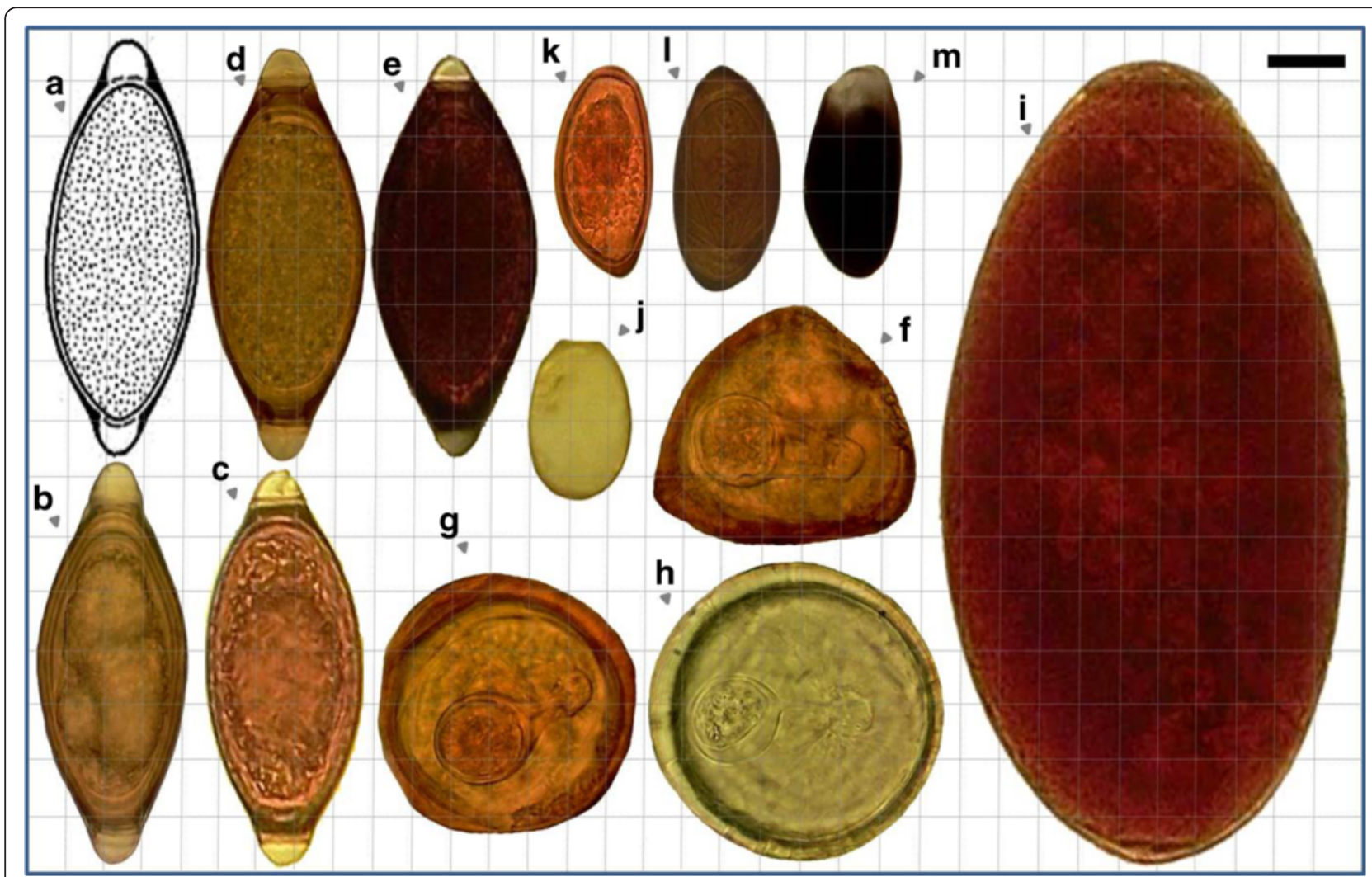

Figure 2 Relative sizes of some of the parasitic (anthropo-zoonotic) particles found in domestic wastewater treatment plants. (a), (b), (c) ,(d), (e) Trichuris spp.; (f) Moniezia expansa (triangular shape with pyriform apparatus); (g), (h) Moniezia spp.; (i) Fasciola hepatica; (j) Eimeria spp. (damaged oocyst); (k), (I) Dicrocoelium dendriticum; (m) Dicrocoelium dendriticum (damaged due to the aeration process) (Photographed under the light microscope at 1000x magnification using by Samsung Mobile, GT-B5512) (Bar showing 20 um). 


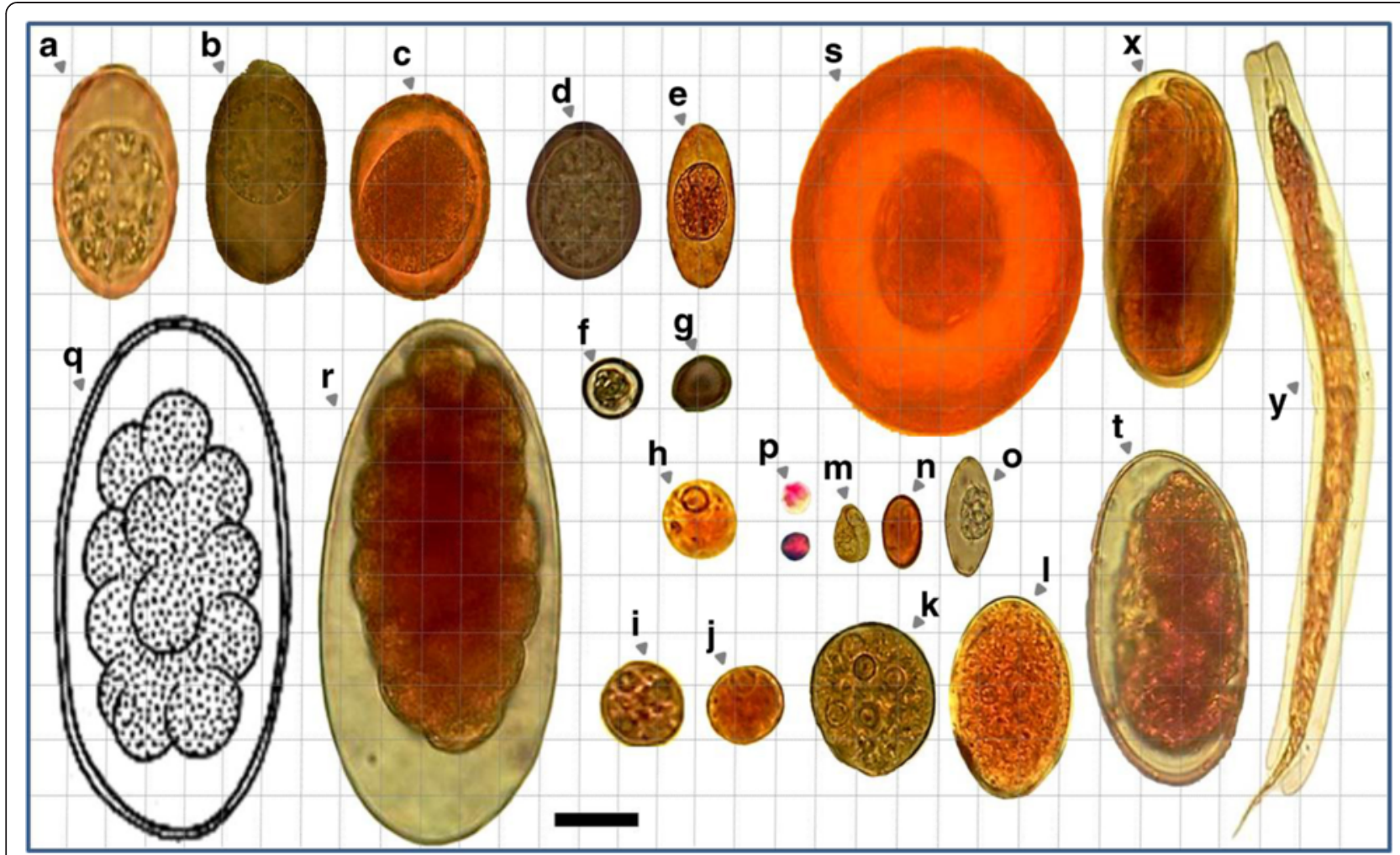

Figure 3 Relative sizes of some of the parasitic (anthropo-zoonotic) particles found in WWTPs and SWWTPs. a) Eimeria spp.; (b) Eimeria spp.; (c), (d), (e), (f), (g) coccidian spp. (This oocyst is typical of Eimeria spp. found in ruminant feces. The micropyle cap would indicate that this specimen came from sheep or goats. Cattle coccidia usually don't have micropyle caps) (h) Entamoeba spp. (E. ovis/debliecki/dilimani/bovis); (i) Entamoeba wenyoni; (j), (k), (l) Entamoeba coli; (m) Chilomastix mesnili; (n) Giardia duodenalis; o) Isospora spp; (p) Cryptosporidium spp. (probably C. andersoni or parvum); (q), (r) Trichostrongylus spp.; (s) Hymenolepis diminuta; (t) hookworms; (x) Rhabditis spp. (or probably Strongyloides); (y) Free living larvae (probably Rhabditidae) (Bar showing $20 \mu \mathrm{m}$ ).

from $1.2 \times 10^{1}$ to $2.9 \times 10^{1}$ and from $9.6 \times 10^{2}$ to $1.9 \times 10^{3}$, respectively (Figure 5).

In the slaughterhouse treatment plants, the estimated number of eggs and (oo)cysts per liter of wastewater influents ranged from $1.6 \times 10^{3}$ to $4.9 \times 10^{3}$ and $31 \times 10^{3}$ to $60 \times 10^{3}$, respectively (Figure 5). Parasite quantification is necessary to evaluate the impact of the wastewater treatment processes on the prevalence of helminth eggs and protozoan (oo)cysts. The geometric mean concentrations of (oo)cysts and eggs per liter of wastewaters are shown in Figure 6.

In livestock wastewaters, eggs belonging to 3 groups of parasitic helminths were identified: the nematodes Trichuris spp., Trichostrongylus spp., the cestodes Moniezia expansa and the trematodes Fasciola hepatica and Dicrocoelum dendriticum. In urban wastewaters, eggs of 4 groups of helminths were observed: hookworms (Ancylostoma duodenale and Necator americanus), Hymenolepis spp. and Rhabditis spp. In these plants, (oo)cysts of 6 groups of parasitic protozoa were found: Giardia spp., Entamoeba spp., Cryptosporidium spp., Eimeria spp., Isospora spp. and Chilomastix mesnili (Figures 2, 3 and 4).
Entamoeba spp., the most commonly encountered cysts, were frequently found $(60.9 \%)$ in urban raw wastewaters (Figure 7).

Sporolated and unsporolated oocysts of Eimeria spp. were frequently observed $(56.1 \%)$ in slaughterhouse wastewater influents (Figure 7).

The highest number of egg in urban and livestock wastewaters was attributed to the nematodes Rhabditis (or probably Strongyloides) (47\%) and Trichostrongylus (36\%), respectively (Figure 7).

There were a large number of the cystic form particles, with a size of about $40-45 \mu$, and many pseudo-parasitic structures including protozoan (oo)cyst like particles and helminth egg like particles that we were unable to identify most of them (Figure 4).

We found many type of the small flagellates and amoebas in the raw and treated wastewaters that were rarely encountered.

The types of free-living protozoa and microorganisms in treated wasewater samples including rotifers, water bears, testate amoebas (Arcella spp. and Euglypha spp.), peritrichs (Epistylis spp, Vorticella spp.), Carnivorous 


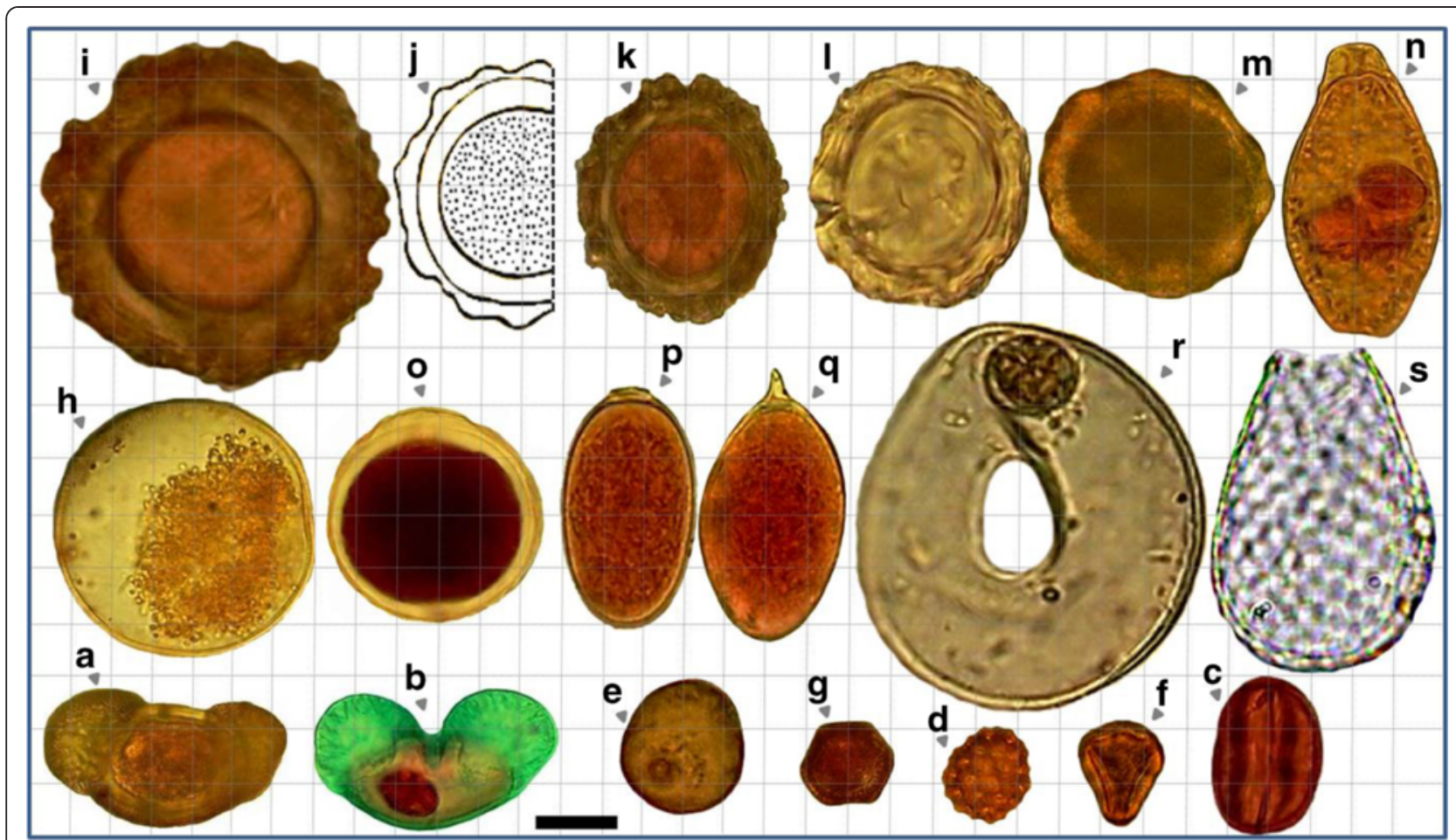

Figure 4 Relative sizes of some of the pseudo-parasitic particles including pollens, free living protozoa and their fossils found in WWTPs and SWWTPs. (a), (b) Pollen grain (Pinus contorta, Family Pinaceae); (b) Pollen grain stained with trichrome; (c) pollen grain (Eriogonum crocatum, Grain Type: Tricolporate); (d) pollen grain (Atriplex patula, Grain Type: Periporate); (e) pollen grain; (f) pollen grain (Eucaliptus globulus, Myrtaceae Family); (g) pollen grain; (h) pecan pollen grain; (i), (k), (l), (m) Ascaris egg-like particles in raw domestic wastewaters; (j) Ascaris lumbricoides; (n) Epistylis spp.; (o) parasite egg- or oocyst-like particle in municipal raw wastewaters; (p), (q) Trematodes egg like particles in raw domestic wastewaters; (r) Arcella discoides; (s) Euglypha spp. (Bar showing 20 um).

ciliates (Acineria uncinata and Plagiocampa rouxi), Bodo spp. and Amoeba spp. (cysts and trophozoites of unshelled amoebas) were also observed (Figure 4).

\section{Removal efficiency of treatment plants}

The overall average reduction in protozoan (oo)cysts $(80.7 \%)$ was significant $(P<0.05)$ in all plants (Table 2$)$. A similar reduction was observed in helminth eggs by municipal WWTPs and livestock SWWTPs $(P<0.05)$; however, the difference in reduction was not significant $(P>0.110)$ in WWTP 3 (Table 3$)$.

The rate of egg overall removal in plants 1, 2, 3, 4 and 5 was 94.8, 95, 95.5, 95.5 and 95.7\%, respectively (Table 4).

Overall removal efficiencies of protozoa (oo)cysts were also $81,83.6,85.8,79.3$ and $80.9 \%$ for plansts $1,2,3,4$ and 5 , respectively (Table 4).

\section{Discussion}

The role played by animal and human wastewaters as sources of parasitic pathogens infecting human is very significant [19].

Many of these intestinal parasites of domestic animals are zoonotic and can be transmitted to humans through ingestion of eggs or (oo)cysts in contamintated water and food (vegetables) and those that do not cause human disease cause severe disease in livestock and have the potential to cause substantial economic losses.

The infected hosts, whether human or animal, shed large numbers of (oo)cysts and eggs via the faeces into the environment, and these parasites are very resistant and may survive in the environment for over a year $[20,21]$.

Moreover, disinfection processes cannot destroy protozoa (oo)cyst and helminths egg, and they have been found in the final effluents of treatment plants [22].

In this study 108 samples were analysed in order to compare the presence of parasitic fauna in untreated and treated wastewaters contaminated by human and livestock feces.

In urban wastewater samples, Entamoeba coli, Entamoeba histolyticaldispar/moshkovskii, Giardia spp., Isospora spp., Cryptosporidium spp. and Chilomastix mesnili were found.

Our investigation of the municipal treatment plants revealed that Entamoeba spp. and Giardia spp. were ubiquitous, whereas Cryptosporidium spp. were quite rare. Results reported in our study correspond with those from 


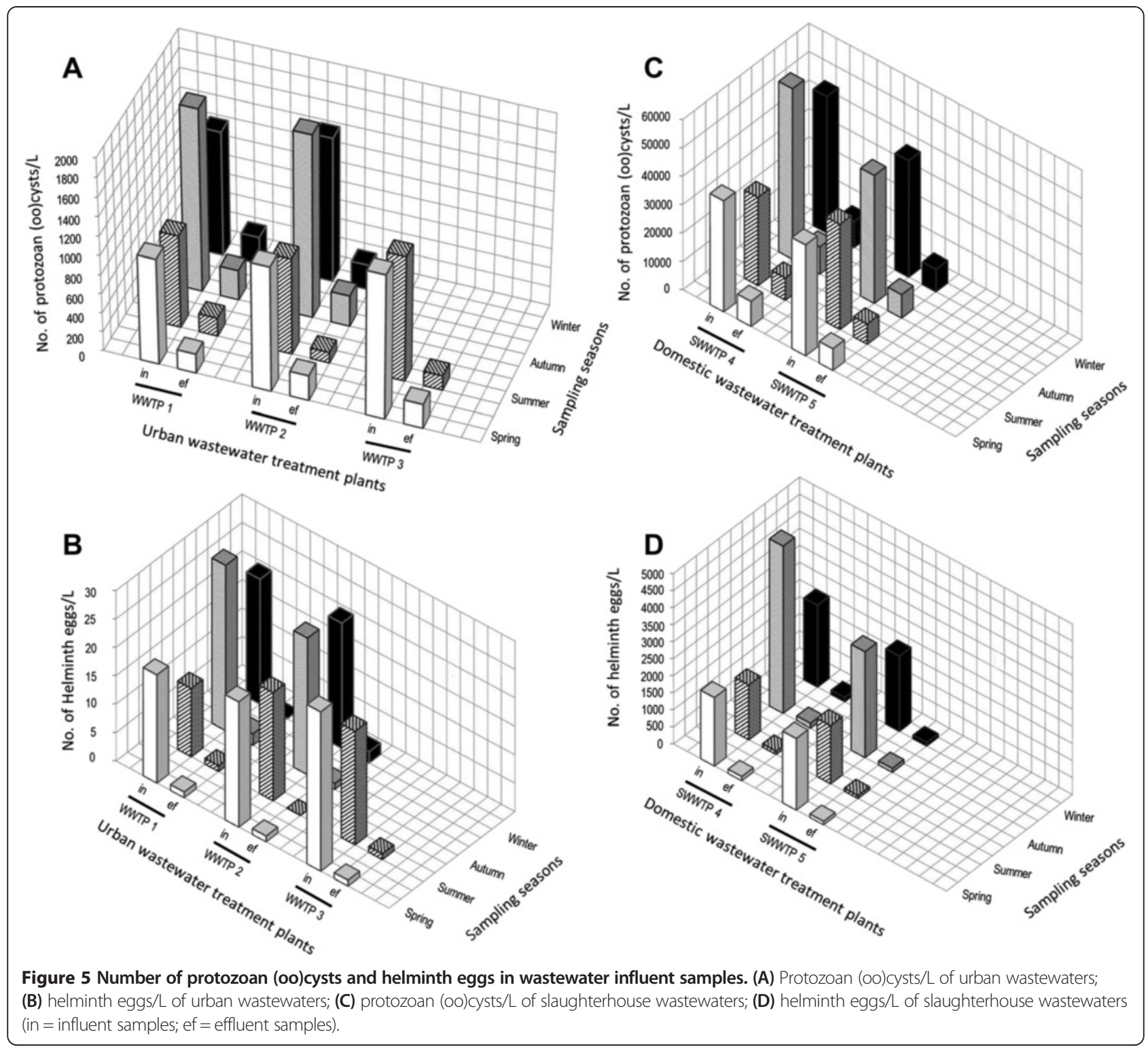

studies published in several countries. Studies carried out in Italia [13,23], China [24], France [25], Malaysia [26], Tunisia $[27,28]$ reported a prominence of Giardia duodenalis and Entamoeba spp. in municipal raw wastewaters. In a recent study conducted by Kitajima and colleagues [29] in the USA, 24 raw wastewater samples from 2 municipal treatment plants were analyzed for the presence of Giardia and Cryptosporidium, that the mean concentration of cysts in the influent has been higher than that of oocysts (4800-6400 versus 74-100 (oo)cysts per liter).

In domestic wastewater samples, Eimeria spp., Entamoeba spp. and Giardia duodenalis were frequently descried.

Similar prevalence rates were reported in raw wastewater collected at a slaughterhouse treatment plant in Tabriz, a city in the northwest of Iran, where the species of E. ahsata, E. ovina, E. Faurei, E. parva, E. pallida and E. intricata were identified [30].

In our study, some of the uni-, tetra-, and octanucleated cyst-forming Entamoeba species were detected. Entamoeba wenyoni in goats is a species of amoebas that has octanucleated cysts. The taxonomic status of these uninucleated Entamoeba species over the years has been confusing. They have been identified in cattle, sheep and goats, and have been given separate names, such as E. bovis in cattle, E. ovis in sheep and $E$. debliecki in goats. However, the various species cannot be distinguished from each other morphologically, and whether they occur in humans or are even genetically distinct remains to be established [31].

The types of helminths ova were observed in this study included gastrointestinal nematodes, cestodes and trematodes. 

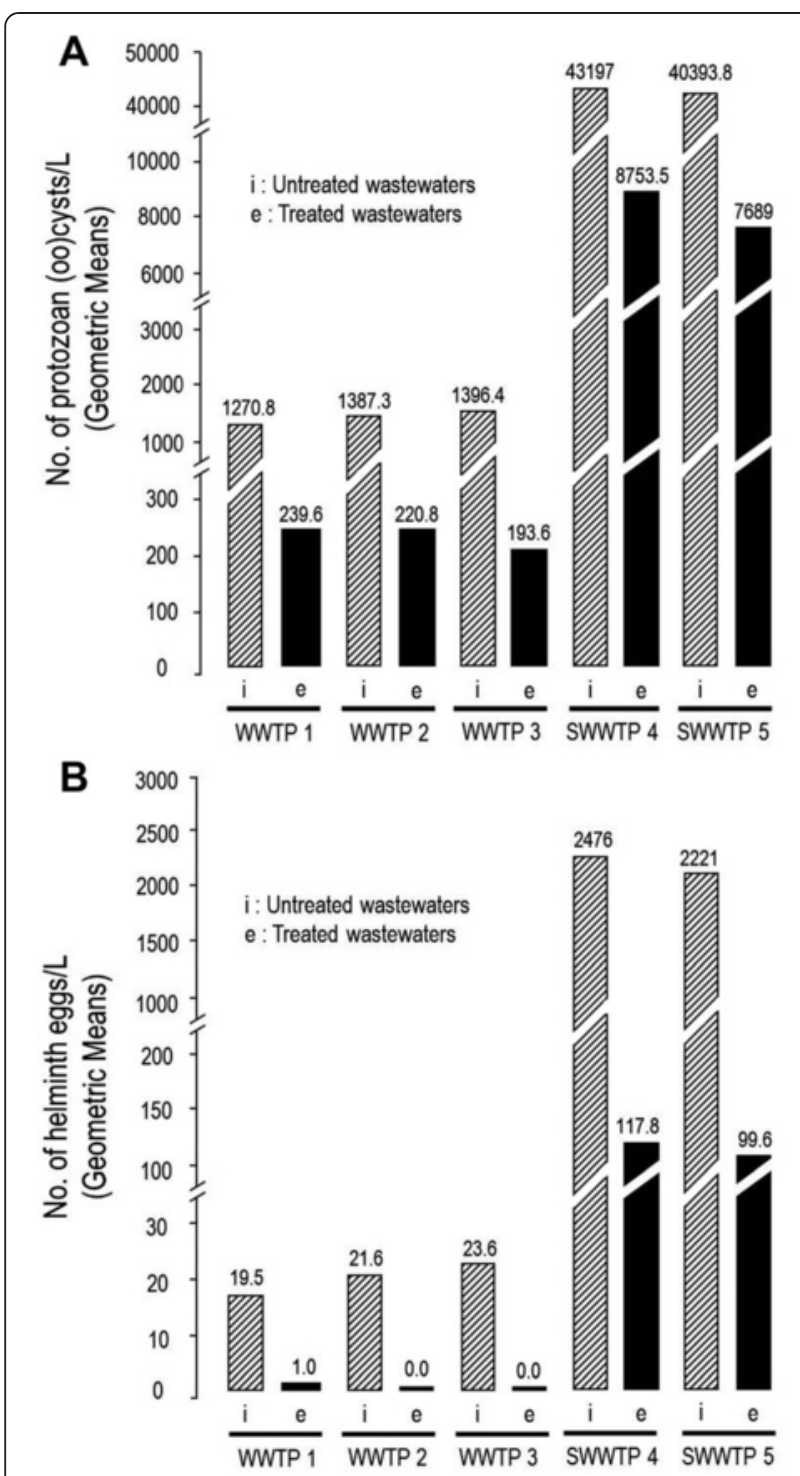

Figure 6 Geometric mean concentrations of protozoan (oo)cysts (A), and helminth eggs (B) per liter of raw and treated wastewater samples from urban (WWTPs) and domestic wastewater tratment plants (SWWTPs).

In the current study, eggs of 5 genus of parasitic helminths were detected in livestock wastewaters: Trichostrongylus spp., Moniezia spp., Fasciola hepatica, Trichuris spp. and Dicrocoelum dendriticum.

We also found eggs of 4 genus of parasitic helminths in municipal wastewaters: hookworms (Ancylostoma duodenale and Necator americanus), Hymenolepis diminuta and Rhabditis spp. (thin-shell eggs and rhabditoid larvae). These eggs and larvae may be related to the free living forms of Strongyloides stercoralis.

It was difficult to distinguish individual species of some parasitic helminths whose eggs and larvae were observed (Strongyloides spp, Rhabditis spp., Trichostrongylus spp. and hookworms), and due to the other objectives pursued in our research project and financial constraints, we did not incubate the above mentioned nematode eggs in order to test their viability.

Results reported in our study correspond with those from studies published in Tehran, Isfahan and Shahrekord cities by our colleagues [10,32].

In our study, helminth ova content in municipal raw wastewater was lower than that reported by Sharafi et al. [33].

Raw wastewater helminth ova contamination found in our study is higher than those of reported for developed countries such as the United State America (1-8 egg per liter) and France ( 9 egg per liter) and is lower than those of reported for developing countries such as Brazil (166-202 egg per liter), Morocco (840 egg per liter), Jordan (300 egg per liter) [34].

We never found eggs of Ascaris, Taenia saginata, Enterobius vermicularis and Hymenolepis nana in untreated human wastewater samples. Most of the eggs were related to aquatic and soil nematodes that are nonpathogenic and the causative agent of spurious infection in humans. In most other studies, these nematode eggs have been reported as Strongyles.

It could stem from the fact that the prevalence of these entric parasites is low in Tehran in the recent years and the fact that eggs of Enterobius vermicularis and Hymenolepis nana cannot survive in wastewater and are quickly destroyed [35]. E. vermicularis and $H$. nana have a direct life cycle and this probably is the secret of their survival.

However, we found some intact eggs of Hymenolepis diminuta in urban raw wastewater. This cestode is a common parasite of rats living in sewage drains.

This has led to the suggestion that the enumeration of enteric parasites in wastewaters can be used as an indicator of infection level within a community [36].

Results of parasite removal efficiencies of treatment plants from each of these studies are not strictly comparable since treatment processes were done on different ways. In addition, because of differences in analyses methodologies, the timeframes in which studies were undertaken and how and where samples were collected.

The overall removal efficiency ranged from 79.3 to $85.8 \%$ for (oo)cysts and from 94.8 to $95.7 \%$ for eggs at the different plants, which is consistent with estimates from other treatment plants that use similar processes $[10,33]$. Helminth eggs were generally removed more effectively than protozoan (oo)cysts.

Performance for secondary treatment systems for egg removal range from 88 to $97 \%$, whereas removal of (oo) cyst is more variable ranging from 80 to $97 \%$ [37].

The highest egg removal efficiency was at SWWTP5 (95.7\%) and the highest (oo)cysts removal efficiency was 

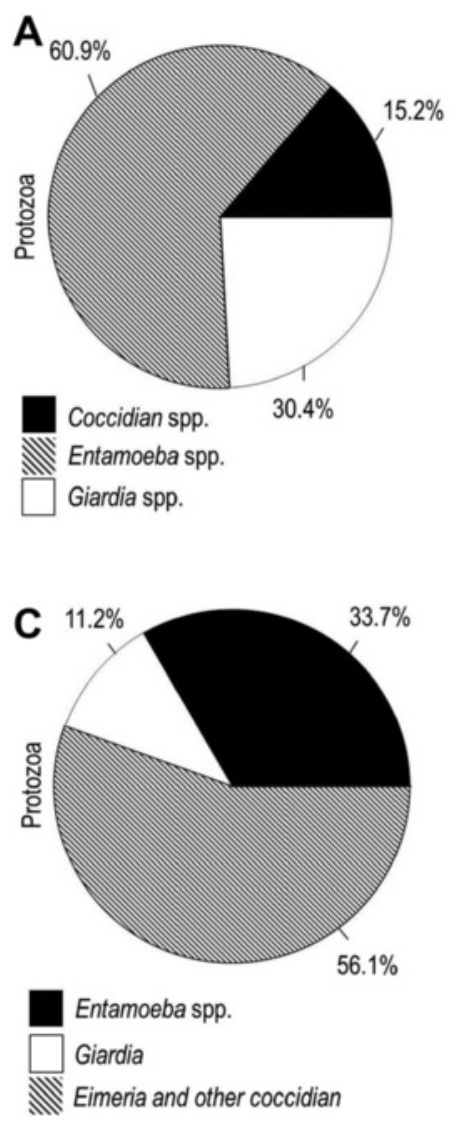
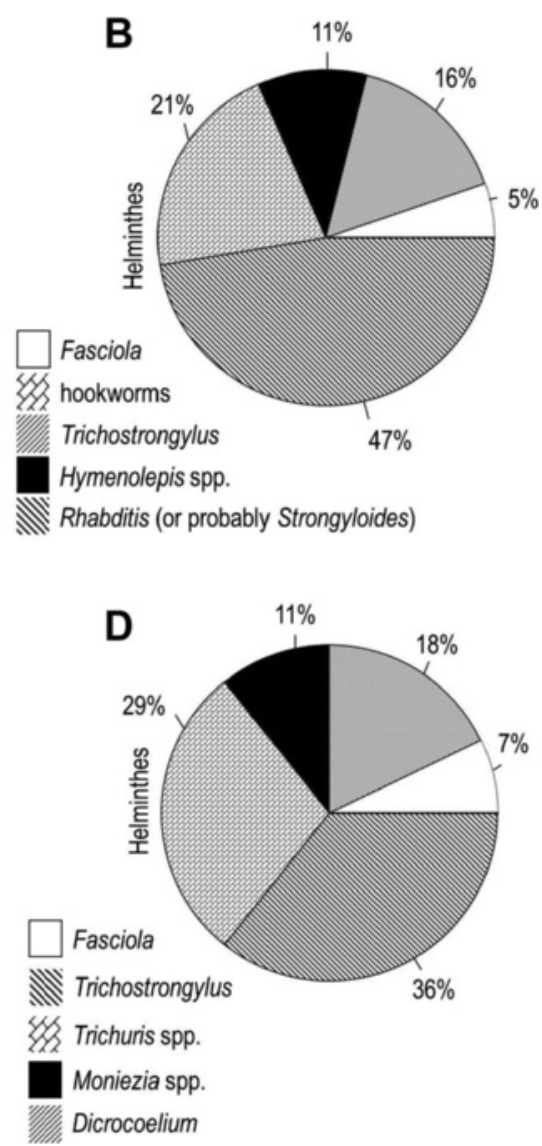

Figure 7 Cumulative percentages of protozoa (oo)cysts and helminth eggs in raw wastewaters. (A) and (B) municipal wastewaters; (C) and (D) slaughterhouse wastewaters.

at WWTP3, perhaps as a consequence of employing the trickling filter followed by activated sludge as secondary treatment system.

In the UK Robertson and colleagues reported more variable protozoan removal of $15-99 \%$ in activated sludge compared to $5-85 \%$ removal in trickling filters but no significant difference in efficacy of protozoan removal was found between the two processes [38].

Table 2 The mean concentrations of protozoan (0o)cyst in raw and treated wastewaters

\begin{tabular}{|c|c|c|c|c|}
\hline \multirow{2}{*}{$\begin{array}{l}\text { Wastewater } \\
\text { treatment } \\
\text { plants }\end{array}$} & \multicolumn{2}{|c|}{$\begin{array}{l}{ }^{\dagger} \text { No. of protozoan (oo)cysts/L } \\
\text { samples }\end{array}$} & \multirow[t]{2}{*}{$\begin{array}{l}\text { Mean } \\
\text { difference }\end{array}$} & \multirow[t]{2}{*}{ P-value } \\
\hline & Influent & Effluent & & \\
\hline WWTP1 & $1315.0 \pm 414.2$ & $245.0 \pm 59.2$ & 1070.0 & 0.010 \\
\hline WWTP2 & $1425.0 \pm 377.5$ & $237.5 \pm 89.6$ & 1187.5 & 0.004 \\
\hline WWTP3 & $1400.0 \pm 141.4$ & $200.0 \pm 70.7$ & 1200.0 & 0.027 \\
\hline SWWTP4 & $44500.0 \pm 12449.0$ & $8775.0 \pm 694.6$ & 35725.0 & 0.009 \\
\hline SWWTP5 & $40500.0 \pm 3415.7$ & $7700.0 \pm 469.0$ & 32800.0 & $<0.001$ \\
\hline
\end{tabular}

${ }^{\dagger}$ Mean \pm SD.
The overall mean reduction in protozoan (oo)cysts $(80.7 \%)$ was significant $(P<0.05)$ in municipal WWTPs. A similar reduction was also observed in helminth eggs by municipal WWTPs $(P<0.05)$. The difference in reduction was not significant $(P>0.110)$ in WWTP 3; however, the number of egg in wastewater effluents of the three urban plants was in compliance with the WHO parasitological guideline $(<1$ nematode per liter) required for irrigation purposes.

The activated sludge process was employed in both SWWTP 1 and SWWTP 2, and their overall mean removal efficiencies were $79.3 \pm 4.1$ and $80.9 \pm 0.5$ for (oo) cysts and, $95 \pm 1.5$ and $95.5 \pm 0.7$ for eggs. In these plants, the overall mean reduction of (oo)cysts and eggs was significant $(P<0.05)$; however, the number of egg in treated wastewater was not in compliance with the WHO parasitological guidelines.

However, it should be noted that the two slaughterhouse plants were too old and there was no one to give us enough information about the plants.

In these abattoirs, we observed that the rumen contents of slaughtered animals were shipped separately and 
Table 3 The mean concentrations of helminth egg in raw and treated wastewaters

\begin{tabular}{|c|c|c|c|c|}
\hline \multirow{2}{*}{$\begin{array}{l}\text { Wastewater } \\
\text { treatment } \\
\text { plants }\end{array}$} & \multicolumn{2}{|c|}{${ }^{\dagger}$ No. helminth eggs/L samples } & \multirow{2}{*}{$\begin{array}{l}\text { Mean } \\
\text { difference }\end{array}$} & \multirow[t]{2}{*}{ P-value } \\
\hline & Influent & Effluent & & \\
\hline WWTP1 & $20.5 \pm 7.0$ & $1.0 \pm 0.8$ & 19.5 & 0.010 \\
\hline WWTP2 & $21.8 \pm 2.1$ & $1.0 \pm 0.8$ & 20.8 & $<0.001$ \\
\hline WWTP3 & $24.0 \pm 5.7$ & $1.0 \pm 0.0$ & 23.0 & 0.110 \\
\hline SWWTP4 & $2725.0 \pm 1486.3$ & $118.0 \pm 16.7$ & 2607.0 & 0.038 \\
\hline SWWTP5 & $2275.0 \pm 76.8$ & $100.0 \pm 9.5$ & 2175.0 & 0.005 \\
\hline
\end{tabular}

used for agricultural-land fertilization and hence, it is thought that the use of slaughterhouse wastewater treatment plant is symbolic.

In the present study, in relation to the raw wastewater samples which were analysed by centrifugal-(waterether) concentration procedure, primary sedimentation resulted in deposition of all particles and secondary sedimentation (the water-ether concentration) resulted in less turbid samples which could be more easily analysed with microscopic method. The use of this procedure significantly improves parasite (oo)cyst and egg purification, particularly for very turbid samples, and is recommended for use in epidemiological studies in which not only (oo) cyst and ova enumeration but also viability assessment are required.

Disadvantage of the membrane filter acetone-dissolution method is the hardening of the pellet containing particles after the centrifugation step and contributes to the overall $\geq 30$ loss of parasitic particles. In addition, the study conducted by Carreno et al. found that the exposure of Cryptosporidium oocysts to solutions used for cellulose acetate membrane dissolution filtration reduce their infectivity in HCT-8 cells [39].

The RM method could potentially be used for monitoring parasitic particles in treated wastewater samples and not raw wastewaters in which contain high concentrations of suspended solids.

In the Bailenger method, background solids from the raw wastewater that are immersed in supernatant, not settled solids and particles with a density $>1.05$, may have interfered with the precipitation of coccidian oocysts and other protozoan cysts, hence contributing to the overall $30-50 \%$ loss.

Dead (oo)cysts are lighter than live (oo)cysts and their settlement is not coincide with the deposition of live (oo)cysts. Therefore, the modified Bailenger method selectively concentrate viable (oo)cysts and more time may be required for settling parasite particles.

We found some of parasite particles consisting of helminth ova and protozoan (oo)cyst (along with trophozoite forms) in municipal and domestic treated wasewater samples.

Also, we found some of free-living protozoa in treated wasewater samples. A complete list of 228 species of protozoa has been reported by [40]. These microorganisms are commonly found in activated sludge and may be mistaken with human parasites.

Disinfection processes in the domestic and municipal wastewater treatment plants cannot destroy protozoa cyst and helminths egg, and they have been found in the final effluents of treatment plants $[3,4,41]$.

Our data provide the first information about the distribution of the zoonotic parasitic particles in wastewater samples from treatment plants and slaughterhouses in Iran. A few studies described the presence of anthroponotic parasites in comparison with zoonotic parasites in faecal samples $[25,42,43]$.

\section{Conclusions}

According to the results the efficiency of removal of nematode eggs and protozoan (oo)cysts in domestic wastewater treatment plants not only is not in compliance with the guidelines for the microbiological quality

Table 4 Overall mean removal efficiency of treatment plants for (0o)cysts and eggs

\begin{tabular}{|c|c|c|c|c|c|c|c|c|c|c|}
\hline \multirow[t]{2}{*}{ Sampling seasons } & \multicolumn{2}{|c|}{$\begin{array}{l}\text { WWTP1 } \\
\text { Removal efficiency* }\end{array}$} & \multicolumn{2}{|c|}{$\begin{array}{l}\text { WWTP } 2 \\
\text { Removal efficiency }\end{array}$} & \multicolumn{2}{|c|}{$\begin{array}{l}\text { WWTP } 3 \\
\text { Removal efficiency }\end{array}$} & \multicolumn{2}{|c|}{$\begin{array}{l}\text { SWWTP } 4 \\
\text { Removal efficiency }\end{array}$} & \multicolumn{2}{|c|}{$\begin{array}{l}\text { SWWTP } 5 \\
\text { Removal efficiency }\end{array}$} \\
\hline & $\begin{array}{l}\text { Cysts and } \\
\text { oocysts }\end{array}$ & Eggs & $\begin{array}{l}\text { Cysts and } \\
\text { oocysts }\end{array}$ & Eggs & $\begin{array}{l}\text { Cysts and } \\
\text { oocysts }\end{array}$ & Eggs & $\begin{array}{l}\text { Cysts and } \\
\text { oocysts }\end{array}$ & Eggs & $\begin{array}{l}\text { Cysts and } \\
\text { oocysts }\end{array}$ & Eggs \\
\hline Spring & 81.8 & 94.7 & 80 & 95.4 & 83.3 & 92.9 & 77.4 & 94 & 80.5 & 95.3 \\
\hline Summer & 80.2 & 91.7 & 89 & 94.7 & 88.4 & 95 & 74.8 & 94 & 80.8 & 94.7 \\
\hline Autumn & 83.6 & 93.1 & 83.1 & 91.6 & $N D^{* *}$ & ND & 84.3 & 97.2 & 81.7 & 96.3 \\
\hline Winter & 78.4 & 95.4 & 82.6 & 90.9 & ND & ND & 81 & 94.8 & 80.7 & 95.4 \\
\hline Overall mean $\pm \mathrm{SD}^{\dagger}$ & $81 \pm 2$ & $93.7 \pm 1.6$ & $83.6 \pm 3.8$ & $95.5 \pm 3.7$ & $85.8 \pm 3.6$ & $95.7 \pm 0.9$ & $79.3 \pm 4.1$ & $95 \pm 1.5$ & $80.9 \pm 0.5$ & $95.5 \pm 0.7$ \\
\hline
\end{tabular}

*Removal efficiency calculated as a persentage (\%).

${ }^{*} \mathrm{ND}$, no data.

${ }^{\dagger}$ Mean removal efficiency (\%) $\pm \mathrm{SD}$.

Results are expressed as the mean percentage removal efficiency and \pm SD . 
of treated wastewater used in agriculture but it also is at an alarming rate.

The release of contaminated outflows into surface waters and the use of these contaminated effluents for irrigation activities could increase the risk of human infection with these zoonotic parasites through the consumption of raw fruits and vegetables.

The study results revealed that the efficacy of removal of nematode ova in urban wastewater treatment plants, and not protozoan (oo)cysts, is in compliance with the WHO parasitological guideline ( $<1$ nematode per liter) required for irrigation purposes.

This emphasizes the importance of the protozological control of effluents from urban wastewater treatment plants and the need for regulations that establish the acceptable concentrations of protozoan (oo)cysts based on the use of effluents, i.e., if they should be recycled in the cities for public, for industry, or for irrigation of corps.

However, in many areas, urban wastwater is directly used for the irrigation of corps and animal waste is used for agricultural-land fertilization and hence, these corps are contaminated with some of the zoonotic enteric parasites. Therefore, this is a way for these pathogens to travel further up the food chain, and this could be potential health risk associated with the agriculture application of sludges, manures and raw wastewaters for agricultural irrigation.

\begin{abstract}
Abbreviations
WWTPs: Wastewater treatment plants; SWWTPs: Slaughterhouse wastewater treatment plants; BOD: Biochemical oxygen demand; TSS: Total suspended solids; A2/O: Anaerobic/anoxic/oxic; NTU: Nephelometric turbidity unit; MB: Modified Bailenger method; RM: Scraping and rinsing of membrane method; ADM: Acetone-dissolution method; CC: Centrifugal-(water-ether) concentration method.
\end{abstract}

\section{Competing interests}

The authors declare that they have no competing interests.

\section{Authors' contributions}

The overall implementation of this study was the results of efforts of all authors. All authors read and approved the final manuscript.

\section{Acknowledgement \\ We thank Dr. Hamidreza Tashayoi and Mr. Rouhi at the Iran Water and Wastewater Treatment Company for their administrative cooperation. We are also grateful to Dr. Ahmadreza Meamar for providing Giardia cysts and to Dr. Khadijeh Khanaliha, Fatemeh Tarighi, Shohreh Farnia, Tahereh Rezaeian, Sorour Charehdar and Dr. Mohhamadbagher Molaei-Rad for their assistance in examination of wastewater. This result is a part of Ph.D. thesis for receiving Ph.D. degree in medical parasitology from the school of Public Health Tehran University of Medical Sciences. This study received financial support from research grant 92-02-160-23616, entitled "Assessment of phenotypic and genotypic of Giardia and Cryptosporidium in the influent and in the effluent of human and domestic animal wastewater treatment plants of Tehran" of the Institute for Environmental Research (IER), Tehran University of Medical Sciences, and Center for Research of Endemic Parasites of Iran (CREPI), Tehran University of Medical Sciences.}

\section{Author details}

'Department of Medical Parasitology and Mycology, School of Public Health, Tehran University of Medical Sciences, Tehran, Iran. ${ }^{2}$ Department of Environmental Health Engineering, School of Public Health, and Center for
Water Quality Research, Institute for Environmental Research, Tehran University of Medical Sciences, Tehran, Iran. ${ }^{3}$ Center for Research of Endemic Parasites of Iran (CREPI), Tehran University of Medical Sciences, Tehran, Iran.

Received: 19 August 2014 Accepted: 6 January 2015

Published online: 25 January 2015

\section{References}

1. Moe $\mathrm{CL}$, Rheingans RD. Global challenges in water, sanitation and health. J Water Health. 2006:4 Suppl 1:41-5.

2. Hussain I, Raschid L, Hanjra MA, Marikar F, van der Hoek W. Wastewater use in agriculture: review of impacts and methodological issues in valuing impacts. Colombo, Sri Lanka: International Water Management Institute; 2002.

3. Levine $A D$, Asano $T$. Recovering sustainable water from wastewater. Environ Sci Technol. 2004;38:201A-8A.

4. Cai L, Zhang T. Detecting human bacterial pathogens in wastewater treatment plants by a high-throughput shotgun sequencing technique. Environ Sci Technol. 2013;47:5433-41.

5. Huang DB, White AC. An updated review on Cryptosporidium and Giardia. Gastroenterol Clin North Am. 2006;35:291-314.

6. Karanis P, Kourenti C, Smith H. Waterborne transmission of protozoan parasites: a worldwide review of outbreaks and lessons learnt. J Water Health. 2007:5:1-38.

7. WHO reports and collaborative reports. Control of foodborne trematode infections, Technical Report Series 849. World Health Organ Tech Rep Ser. 1995;849:1-157. http://apps.who.int/iris/handle/10665/41544.

8. Guandalini S. Textbook of Pediatric Gastroenterology and Nutrition. Florida, United States: CRC Press; 2004

9. Gharavi M, Jahani M, Rokni M. Parasitic contamination of vegetables from farms and markets in Tehran. Iranian J Pub Health. 2002;31:83-6.

10. Mahvi A, Kia E. Helminth eggs in raw and treated wastewater in the Islamic Republic of Iran. East Mediterr Health J. 2006;12:137-43.

11. Fallah E, Mahdavi Poor B, Jamali R, Hatam-Nahavandi K, Asgharzadeh M. Molecular characterization of Cryptosporidium isolates from cattle in a slaughterhouse in Tabriz, Northwestern Iran. J Biol Sci. 2008;8:639-43.

12. Mahmoudi M, Ashrafi K, Abedinzadeh H, Tahvildar-Bideruni F, Haghighi A, Bandehpour M, et al. Development of sensitive detection of Cryptosporidium and Giardia from surface water in Iran. Iranian J Parasitol. 2011;6:43-51.

13. Cacciò SM, De Giacomo M, Aulicino FA, Pozio E. Giardia cysts in wastewater treatment plants in Italy. Appl Environ Microbiol. 2003;69:3393-8.

14. Franco RMB, Rocha-Eberhardt R, Cantusio Neto R. Occurrence of Cryptosporidium oocysts and Giardia cysts in raw water from the Atibaia river, Campinas, Brazil. Rev Inst Med Trop São Paulo. 2001;43(2):109-11.

15. Skotarczak B. Methods for parasitic protozoans detection in the environmental samples. Parasite. 2009;16:183-90.

16. Bukhari Z, Smith H. Effect of three concentration techniques on viability of Cryptosporidium parvum oocysts recovered from bovine feces. J Clin Microbiol. 1995;33:2592-5.

17. Zajac AM, Conboy GA. Veterinary Clinical Parasitology. Hoboken, New Jersey: John Wiley \& Sons; 2012.

18. Ayres RM, Mara DD. Analysis of Wastewater for use in Agriculture: a Laboratory Manual of Parasitological and Bacteriological Techniques. Geneva: World Health Organization; 1996.

19. Dufour AP, Dufour A. Animal Wastewater Quality and Human Health. United Kingdom: IWA Publishing; 2012

20. Olson M. Human and animal pathogens in manure. In: Conference on Livestock Options for the Future: 25-27 June 2001. Winnepeg: Manitoba, Canada: Agriculture and Agri-Food Canada; 2001. http://www.gov.mb.ca/ agriculture/livestock/livestockopt/papers/olson.pdf.

21. Wichuk KM, McCartney D. A review of the effectiveness of current timetemperature regulations on pathogen inactivation during composting. J Environ Engin Sci. 2007;6:573-86.

22. Plym-Forshell L. Survival of salmonellas and Ascaris suum eggs in a thermophilic biogas plant. Acta Vet Scand. 1994;36:79-85.

23. Brandonisio O, Portincasa F, Torchetti G, Lacarpia N, Rizzi A, Fumarola L, et al. Giardia and Cryptosporidium in water: evaluation of two concentration methods and occurrence in wastewater. Parassitologia. 2000;42:205-9.

24. Li N, Xiao L, Wang L, Zhao $S$, Zhao X, Duan L, et al. Molecular surveillance of Cryptosporidium spp., Giardia duodenalis, and Enterocytozoon bieneusi by genotyping and subtyping parasites in wastewater. PLoS Negl Trop Dis. 2012;6:e1809. 
25. Bertrand I, Schwartzbrod J. Detection and genotyping of Giardia duodenalis in wastewater: RELATION between assemblages and faecal contamination origin. Water Res. 2007;41:3675-82.

26. Lim Y, Wan Hafiz W, Nissapatom V. Reduction of Cryptosporidium and Giardia by sewage treatment processes. Tropical Biomed. 2007;24:95-104.

27. Khouja LBA, Cama V Xiao L. Parasitic contamination in wastewater and sludge samples in Tunisia using three different detection techniques. Parasitol Res. 2010;107:109-16.

28. Layla BA, Yang W, Widmer G, Cama V, Ortega Y, Xiao L. Survey and genetic characterization of wastewater in Tunisia for Cryptosporidium spp., Giardia duodenalis, Enterocytozoon bieneusi, Cyclospora cayetanensis and Eimeria spp. J Water Health. 2012;10:431-44.

29. Kitajima M, Haramoto E, Iker BC, Gerba CP. Occurrence of Cryptosporidium, Giardia, and Cyclospora in influent and effluent water at wastewater treatment plants in Arizona. Sci Total Environ. 2014:484:129-36.

30. Yakhchali M, Zarei M. Prevalence of Eimeria infection in sheep of Tabriz suburb, Iran. Iran J Vet Res. 2008:9:277-80.

31. Verweij JJ, Polderman AM, Clark CG. Genetic variation among human isolates of uninucleated cyst-producing Entamoeba species. J Clin Microbiol. 2001;39:1644-6.

32. Miranzadeh M, Mahmodi S. Investigation into the removal of nematodes eggs in influent and effluent of shoosh wastewater treatment plant. J Water Wastewater. 2002;42:32-6 (In persian)

33. Sharafi K, Fazlzadehdavil M, Pirsaheb M, Derayat J, Hazrati S. The comparison of parasite eggs and protozoan cysts of urban raw wastewater and efficiency of various wastewater treatment systems to remove them. Ecol Eng. 2012;44:244-8.

34. Jimenez B. Helminth ova removal from wastewater for agriculture and aquaculture reuse. Water Sci Technol. 2007;55:485-93.

35. Horak $P$. Helminth eggs in the sludge from three sewage treatment plants in Czechoslovakia. Folia Parasitol . 1992:39:153-7.

36. Jakubowski W, Sykora JL, Sorber CA, Casson LW, Gavaghan PD. Determining giardiasis prevalence by examination of sewage. Water Sci Technol. 1991;24:173-8

37. Mara D, Horan NJ. Handbook of water and wastewater microbiology. 2003 Academic press.

38. Robertson L, Paton CA, Campbell AT, Smith PG, Jackson MH, Gilmour RA, et al. Giardia cysts and Cryptosporidium oocysts at sewage treatment works in Scotland, UK. Water Res. 2000;34:2310-22.

39. Carreno RA, Pokorny NJ, Weir SC, Lee H, Trevors JT. Decrease in Cryptosporidium parvum oocyst infectivity in vitro by using the membrane filter dissolution method for recovering oocysts from water samples. Appl Environ Microbiol. 2001;67:3309-13.

40. Madoni P. Protozoa in wastewater treatment processes: a minireview. Ital J Zool. 2011;78:3-11

41. Toze S. Microbial Pathogens in Wastewater: Literature Review for Urban Water Systems Multi-divisional Research Program. Australia: CSIRO Land and Water; 1997

42. Bjorkman C, Svensson C, Christensson B, de Verdier K. Cryptosporidium parvum and Giardia intestinalis in calf diarrhoea in Sweden. Acta Vet Scand. 2003:44:145-52.

43. Hutchison M, Walters LD, Avery SM, Synge BA, Moore A. Levels of zoonotic agents in British livestock manures. Lett Appl Microbiol. 2004;39:207-14.

\section{Submit your next manuscript to BioMed Central and take full advantage of:}

- Convenient online submission

- Thorough peer review

- No space constraints or color figure charges

- Immediate publication on acceptance

- Inclusion in PubMed, CAS, Scopus and Google Scholar

- Research which is freely available for redistribution 